Pacific Journal of Mathematics

THE DEFICIENCY INDEX OF A THIRD ORDER OPERATOR 


\title{
THE DEFICIENCY INDEX OF A THIRD ORDER OPERATOR
}

\author{
Richard C. Gilbert
}

Let $L$ be a formally selfadjoint third order linear ordinary differential operator defined on $[r, \infty)$. Using a method of Fedorjuk, asymptotic formulas are found for the solutions of $L y=i \sigma y, \sigma \neq 0$. These formulas are used to determine the deficiency index of $L$ when $L$ has polynomial coefficients. As a consequence, the deficiency index is determined for values of the parameters involved for which it has not previously been determined.

1. Introduction. The general form of a third order formally selfadjoint linear ordinary differential operator $L$ can be written

$$
L y=\left(i b_{2} y^{\prime \prime}\right)^{\prime}+\left[\left(2^{-1} i b_{2}^{\prime}+a_{1}\right) y^{\prime}\right]^{\prime}+i b_{1} y^{\prime}+\left(2^{-1} i b_{1}^{\prime}+a_{0}\right) y,
$$

where $a_{0}, a_{1}, b_{1}, b_{2}$ are real functions of $x$ and $b_{2}(x) \neq 0$. (See [4, Ch. 1, $\S 1.5]$. We have assumed sufficient differentiability on the coefficients so that the Dunford and Schwartz form can be written in the form (1).) Unsworth [12] considered the case that $b_{2}(x)=2, b_{1}(x)=2 a x^{\alpha}$, $a_{1}(x)=b x^{\beta}, a_{0}(x)=c x^{\gamma}, 1 \leqq x<\infty$. Using the asymptotic methods of Devinatz [3], Unsworth deduced the deficiency index of $L$ for various values of the parameters $a, b, c, \alpha, \beta, \gamma$. Pfeiffer [10] considered the case $b_{2}(x)=1, b_{1}(x)=a x^{\alpha}, a_{1}(x)=0, a_{0}(x)=c x^{\gamma}$. The purpose of the present article is to obtain by the method of Fedorjuk [6] asymptotic formulas for the solutions of $L y=i \sigma y, \sigma \neq 0$, and to apply these formulas to finding the deficiency index of $L$ for the case $b_{2}(x)=1, b_{1}(x)=a x^{\alpha}$, $a_{1}(x)=b x^{\beta}, a_{0}(x)=c x^{\gamma}$. Although Fedorjuk applied his method only to even order operators, it can be used for odd order operators as well. Shirikyan [11] applied the Fedorjuk method to a certain class of odd order operators. It turns out that the Fedorjuk method applied to the above case yields the deficiency index for values of the parameters different from Unsworth and Pfeiffer.

It is known that, except for a first order operator, a differential operator of order $n$ cannot have deficiency index $(n, p)$ or $(p, n)$, where $p<n$. (See Atkinson [1] or Kogan and Rofe-Beketov [7], [8].) Further, for an operator of order $n=2 \nu-1$ it is known that the deficiency numbers $n_{+}$and $n_{-}$satisfy the inequalities $\nu \leqq n_{+} \leqq 2 \nu-1, \nu-1 \leqq n_{-} \leqq$ $2 \nu-1$, or the same inequalities with $n_{+}$and $n_{-}$interchanged. (See 
Everitt [5] or Kogan and Rofe-Beketov [8].) It follows that the deficiency indices $(2,1),(1,2),(2,2)$ and $(3,3)$, obtained in this paper and by Unsworth and Pfeiffer, are the only possible deficiency indices for a third order operator.

\section{Asymptotic formulas for the solutions of $L y=$} i $\sigma y$. We shall make the following assumptions on the coefficients $a_{0}, a_{1}$, $b_{1}, b_{2}$ of $L$. The need for the various assumptions will be seen as we go along.

In all that follows in this article, it will be necessary in various places to require that $x$ is sufficiently large. We shall therefore assume once and for all that $x_{0}$ is chosen so large that if $x \geqq x_{0}$, then $x$ is sufficiently large in all places where this is needed. We shall also often omit the stipulation $x \geqq x_{0}$ when it is clear from the context that this is needed.

Assumption I. $\quad b_{1}(x), b_{2}(x) \in C^{3}[r, \infty) . \quad a_{0}(x), a_{1}(x) \in C^{2}[r, \infty)$. $b_{2}(x) \neq 0$ for $x \geqq r, \quad b_{2}(x)=1+o(1)$ as $x \rightarrow+\infty$. $a_{0}(x) \neq 0$ for $x \geqq$ $r$. Either $a_{0}(x) \rightarrow+\infty$ and $a_{0}^{\prime}(x)>0$ for $x \geqq x_{0}$, or else $a_{0}(x) \rightarrow-\infty$ and $a_{0}^{\prime}(x)<0$ for $x \geqq x_{0}$.

AsSUMPTION II. $\quad \lim _{x \rightarrow \infty} a_{1} / a_{0}^{1 / 3}=d \neq 3 / 2^{2 / 3}, \quad b_{1} / a_{0}^{2 / 3}=o(1), \quad b_{1}^{\prime} / a_{0}=$ $o(1), b_{2}^{\prime} / a_{0}^{1 / 3}=o(1)$.

AsSUMPTION III. $\quad b_{2}^{\prime \prime} / a_{0}^{2 / 3}=o(1), \quad a_{1}^{\prime} / a_{0}^{2 / 3}=o(1), \quad b_{1}^{\prime \prime} / a_{0}^{4 / 3}=o(1)$, $a_{0}^{\prime} / a_{0}^{4 / 3}=o(1)$.

Assumption IV. $\quad b_{2}^{\prime}$ and $b_{1}^{\prime} / a_{0}^{2 / 3}$ are absolutely integrable on $[r, \infty)$.

Let

$$
f(\lambda, x)=-\lambda^{3}+i m(x) b_{2}^{-1}(x) \lambda^{2}-b_{1}(x) b_{2}^{-1}(x) \lambda+i n(x) b_{2}^{-1}(x),
$$

where

$$
\begin{gathered}
m(x)=2^{-1} i b_{2}^{\prime}(x)+a_{1}(x), \\
n(x)=2^{-1} i b_{1}^{\prime}(x)+a_{0}(x)-i \sigma .
\end{gathered}
$$

Here $\sigma$ is a real constant, $\sigma \neq 0$.

Let

$$
\tau(x)=\left[a_{0}(x) b_{2}^{-1}(x)\right]^{1 / 3}\left[1+\left(b_{1}^{\prime}(x)-2 \sigma\right)\left(2 a_{0}(x)\right)^{-1} i\right]^{1 / 3},
$$

where if $z=\rho e^{i \theta},-\pi<\theta \leqq \pi$, then we take $z^{1 / 3}=\rho^{1 / 3} e^{i \theta / 3}$. Then, 
$\tau^{3}=n b_{2}^{-1}$, and $\tau(x) \neq 0$ for $x \geqq r$.

Putting

$$
\lambda=i \eta \tau(x)
$$

then

$$
f(\lambda, x)=0
$$

becomes

$$
h(\eta, x)=0,
$$

where

(9) $h(\eta, x)=\eta^{3}-m(x)\left[b_{2}(x) \tau(x)\right]^{-1} \eta^{2}-b_{1}(x)\left[b_{2}(x) \tau^{2}(x)\right]^{-1} \eta+1$.

An essential part of the Fedorjuk method is that we should have

$$
\begin{aligned}
& \lim _{x \rightarrow \infty} m(x)\left[b_{2}(x) \tau(x)\right]^{-1}=d+i e_{1}, \\
& \lim _{x \rightarrow \infty} b_{1}(x)\left[b_{2}(x) \tau^{2}(x)\right]^{-1}=d_{2}+i e_{2},
\end{aligned}
$$

where $d+i e_{1}$ and $d_{2}+i e_{2}$ are complex constants. Then, as $x \rightarrow \infty$, $h(\eta, x)$ approaches a polynomial $h_{0}(\eta)$ with constant coefficients. We also want $h_{0}(\eta)=0$ to have distinct roots. For reasons that will appear later we further want as $x \rightarrow \infty$ that $\left|a_{0}(x)\right| \rightarrow \infty$ and that

$$
\tau(x)=a_{0}^{1 / 3}(x)[1+o(1)] .
$$

In I and II we have assumed $a_{0}(x) \rightarrow \pm \infty, b_{2}=1+o(1), b_{1}^{\prime} / a_{0}=o(1)$ in order that (12) and $\left|a_{0}(x)\right| \rightarrow \infty$ might be true. In order to explain the remaining assumptions in I and II, let us note that if (10) and (11) are to be true, we must have

$$
\begin{aligned}
& \lim _{x \rightarrow \infty}\left(b_{2}^{\prime} / a_{0}^{1 / 3}\right)=2 e_{1}, \\
& \lim _{x \rightarrow \infty}\left(a_{1} / a_{0}^{1 / 3}\right)=d, \\
& \lim _{x \rightarrow \infty}\left(b_{1} / a_{0}^{2 / 3}\right)=d_{2},
\end{aligned}
$$


and $e_{2}=0$. But then (13) and our assumptions that $\left|a_{0}\right| \rightarrow \infty$ and $b_{2}=1+o(1)$ imply that $e_{1}=0$. Further, (15) and the assumptions on $a_{0}$ in $I$ and the assumption that $b_{1}^{\prime} / a_{0}^{2 / 3}$ is absolutely integrable on $[r, \infty)$ in IV imply that $d_{2}=0$. Thus, we have explained the reasons for all the limit assumptions in I and II.

From Assumptions I and II we have that

$$
\begin{aligned}
& m(x)\left[b_{2}(x) \tau(x)\right]^{-1}=d+f_{1}(x), \\
& b_{1}(x)\left[b_{2}(x) \tau^{2}(x)\right]^{-1}=f_{2}(x),
\end{aligned}
$$

where $f_{1}(x)=o(1), f_{2}(x)=o(1)$, and $f_{1}(x)$ and $f_{2}(x)$ are continuously differentiable on $[r, \infty)$. It follows that

$$
h(\eta, x)=h_{0}(\eta)-\eta^{2} f_{1}(x)-\eta f_{2}(x)
$$

where

$$
h_{0}(\eta)=\eta^{3}-d \eta^{2}+1
$$

Since we have assumed in II that $d \neq 3 / 2^{2 / 3}, h_{0}(\eta)=0$ has three distinct nonzero roots. If $d<3 / 2^{2 / 3}$, then $h_{0}(\eta)=0$ has one real negative root and two complex conjugate nonreal roots. If $d>3 / 2^{2 / 3}$, then $h_{0}(\eta)=0$ has three distinct real roots, one of which is negative and the other two positive. We denote the roots by $\eta_{01}, \eta_{02}, \eta_{03}$, where $\eta_{01}<\eta_{02}<\eta_{03}$ in the case of three real roots, and $\eta_{01}$ is real and $\operatorname{Im} \eta_{02}>0, \operatorname{Im} \eta_{03}<0$ in the case of one real root. In the case of three real roots, $h^{\prime}\left(\eta_{01}\right)>0$, $h^{\prime}\left(\eta_{02}\right)<0, h^{\prime}\left(\eta_{03}\right)>0$. In the case of one real root, $h^{\prime}\left(\eta_{01}\right)>0$. In every case, $h^{\prime}\left(\eta_{0 k}\right) \neq 0, k=1,2,3$.

According to Bellman [2, p. 26], for $x \geqq x_{0}$, (8) has three distinct roots $\eta_{k}(x), k=1,2,3$ which are given by the formula

$$
\eta_{k}(x)=(2 \pi i)^{-1} \int_{C_{k}} \eta h_{\eta}(\eta, x)[h(\eta, x)]^{-1} d \eta
$$

where $C_{k}$ is a small circle around $\eta_{0 k} . \quad \eta_{k}(x)$ is continuously differentiable, and

$$
\eta_{k}(x)=\eta_{0 k}[1+o(1)]
$$

We have that $h_{\eta}\left(\eta_{k}(x), x\right) \neq 0$, and that $\eta_{k}(x) \neq 0$, for $x \geqq x_{0}$. From (6) one sees that (7) has for $x \geqq x_{0}$, three distinct continuously differentiable nonzero roots $\lambda_{k}(x)$ given by

$$
\lambda_{k}(x)=i \eta_{k}(x) \tau(x), \quad k=1,2,3,
$$


and

$$
\lambda_{k}(x)=i a_{0}^{1 / 3}(x) \eta_{0 k}[1+o(1)]
$$

We have that $f_{\lambda}\left(\lambda_{k}(x), x\right) \neq 0$.

AsSUMPTION V. $\left(b_{2}^{\prime}\right)^{2} / a_{0}^{1 / 3}, \quad\left(b_{2}^{\prime \prime}\right)^{2} / a_{0}, \quad\left(a_{1}^{\prime}\right)^{2} / a_{0}, \quad\left(b_{1}^{\prime}\right)^{2} / a_{0}^{5 / 3}, \quad\left(b_{1}^{\prime \prime}\right)^{2} / a_{0}^{7 / 3}$, $\left(a_{0}^{\prime}\right)^{2} / a_{0}^{7 / 3}, b_{2}^{\prime \prime} / a_{0}^{1 / 3}, b_{2}^{\prime \prime \prime} / a_{0}^{2 / 3}, a_{1}^{\prime \prime} / a_{0}^{2 / 3}, b_{1}^{\prime \prime} / a_{0}, b_{1}^{\prime \prime \prime} / a_{0}^{4 / 3}, a_{0}^{\prime \prime} / a_{0}^{4 / 3}$ are all absolutely integrable on $[r, \infty)$.

Assumption VI. For each pair $j, k$, one of the following is true:

(a) $\operatorname{Re}\left(\lambda_{j}(x)-\lambda_{k}(x)\right) \geqq 0$ for $x \geqq x_{0}$;

(b) $\operatorname{Re}\left(\lambda_{j}(x)-\lambda_{k}(x)\right) \leqq 0$ for $x \geqq x_{0}$, and

$$
\int_{x_{0}}^{\infty} \operatorname{Re}\left(\lambda_{j}(x)-\lambda_{k}(x)\right) d x=-\infty
$$

(c) $\int_{x_{0}}^{\infty} \operatorname{Re}\left(\lambda_{j}(x)-\lambda_{k}(x)\right) d x$ is convergent.

Using Assumptions I-VI, it is now possible to obtain asymptotic formulas for the solutions of the equation

$$
L y=i \sigma y \text {. }
$$

Let $w$ be the column vector with components $w_{1}=y, w_{2}=y^{\prime}, w_{3}=$ $i b_{2} y^{\prime \prime}+m y^{\prime} . \quad(24)$ is then equivalent to the system

$$
w^{\prime}=A(x) w,
$$

where

$$
A(x)=\left(\begin{array}{ccc}
0 & 1 & 0 \\
0 & i m b_{2}^{-1} & -i b_{2}^{-1} \\
-n & -i b_{1} & 0
\end{array}\right)
$$

The eigenvalues of $A(x)$ are the roots of (7), i.e., $\lambda_{k}(x), k=1,2,3$.

Let us now make the transformation

$$
w=T_{0}\left(E+T_{2}\right) z
$$

where $z$ is a column vector with components $z_{1}, z_{2}, z_{3}$, and $T_{0}$ and $T_{2}$ are matrices to be determined, and $E$ is the identity matrix. Then, (25) becomes 
(28)

$$
z^{\prime}=\Lambda_{0} z+\left(\Lambda_{0} T_{2}-T_{2} \Lambda_{0}-T_{0}^{-1} T_{0}^{\prime}\right) z+B(x) z
$$

where

$$
\begin{aligned}
B(x)= & \left(E+T_{2}\right)^{-1}\left[\left(T_{2}^{2} \Lambda_{0}+T_{2} T_{0}^{-1} T_{0}^{\prime}\right)\left(E+T_{2}\right)-T_{2}^{\prime}\right] \\
& -T_{2} \Lambda_{0} T_{2}-T_{0}^{-1} T_{0}^{\prime} T_{2},
\end{aligned}
$$

and

$$
\Lambda_{0}=T_{0}^{-1} A T_{0} .
$$

We shall show that we can choose $T_{0}$ and $T_{2}$ such that for $x \geqq x_{0}, T_{0}^{-1}$ and $\left(E+T_{2}\right)^{-1}$ exist, and $T_{0}^{-1} A T_{0}$ and $\Lambda_{0} T_{2}-T_{2} \Lambda_{0}-T_{0}^{-1} T_{0}^{\prime}$ are diagonal. To that end, we choose $T_{0}$ to be a matrix whose columns are eigenvectors for $A$, namely,

$$
\begin{gathered}
T_{0}=\left(\begin{array}{ccc}
1 & 1 & 1 \\
\lambda_{1} & \lambda_{2} & \lambda_{3} \\
{\left[i b_{2} \lambda_{1}+m\right] \lambda_{1}} & {\left[i b_{2} \lambda_{2}+m\right] \lambda_{2}} & {\left[i b_{2} \lambda_{3}+m\right] \lambda_{3}}
\end{array}\right), \\
T_{0}^{-1}=\left(\begin{array}{lll}
n / \lambda_{1} F_{\lambda}\left(\lambda_{1}, x\right) & -i \lambda_{1} b_{2} / F_{\lambda}\left(\lambda_{1}, x\right) & -1 / F_{\lambda}\left(\lambda_{1}, x\right) \\
n / \lambda_{2} F_{\lambda}\left(\lambda_{2}, x\right) & -i \lambda_{2} b_{2} / F_{\lambda}\left(\lambda_{2}, x\right) & -1 / F_{\lambda}\left(\lambda_{2}, x\right) \\
n / \lambda_{3} F_{\lambda}\left(\lambda_{3}, x\right) & -i \lambda_{3} b_{2} / F_{\lambda}\left(\lambda_{3}, x\right) & -1 / F_{\lambda}\left(\lambda_{3}, x\right)
\end{array}\right),
\end{gathered}
$$

where

$$
F(\lambda, x)=i b_{2} f(\lambda, x) \text {. }
$$

Then, for $x \geqq x_{0}$,

$$
T_{0}^{-1} A T_{0}=\Lambda_{0}=\operatorname{diagonal}\left[\lambda_{j}\right]
$$

We note that

$$
\lim _{x \rightarrow \infty} a_{0}^{-2 / 3}(x) F_{\lambda}\left(\lambda_{\jmath}(x), x\right)=i h_{0}^{\prime}\left(\eta_{0 j}\right)=\rho_{0 j} \exp \left[i \theta_{0 j}\right]
$$

where $-\pi<\theta_{0 j} \leqq \pi, \rho_{0 j}>0$. Let

$$
a_{0}^{-2 / 3}(x) F_{\lambda}\left(\lambda_{j}(x), x\right)=\rho_{j}(x) \exp \left[i \theta_{j}(x)\right]
$$

where $\rho_{j}(x)$ and $\theta_{j}(x)$ are chosen so that $\lim _{x \rightarrow \infty} \rho_{j}(x)=\rho_{0 j}$, and $\lim _{x \rightarrow \infty} \theta_{j}(x)=\theta_{0 j}$. We choose that branch of $\log$ such that for $x \geqq x_{0}$,

$$
\log F_{\lambda}\left(\lambda_{j}(x), x\right)=(2 / 3) \log \left|a_{0}(x)\right|+\log \rho_{j}(x)+i \theta_{j}(x) .
$$

Then, for $t, x \geqq x_{0}$, 


$$
\begin{aligned}
& (d / d x) \log F_{\lambda}\left(\lambda_{j}(x), x\right) \\
& \quad=\left[F_{\lambda \lambda}\left(\lambda_{j}(x), x\right) \lambda_{j}^{\prime}(x)+F_{\lambda x}\left(\lambda_{j}(x), x\right)\right]\left[F_{\lambda}\left(\lambda_{j}(x), x\right)\right]^{-1},
\end{aligned}
$$

(38) $\int_{t}^{x}\left[(d / d s) \log F_{\lambda}(\lambda,(s), s)\right] d s=\log F_{\lambda}\left(\lambda_{j}(x), x\right)-\log F_{\lambda}\left(\lambda_{j}(t), t\right)$,

(39) $\exp \left[(1 / 2) \log F_{\lambda}\left(\lambda_{l}(x), x\right)\right]=[1+o(1)]\left|a_{0}^{1 / 3}(x)\right| \rho_{0 j}^{1 / 2} \exp \left(i \theta_{0 j} / 2\right)$.

Now we note that the elements $\left(T_{0}^{-1} T_{0}^{\prime}\right)_{j k}$ of the matrix $T_{0}^{-1} T_{0}^{\prime}$ are given for $x \geqq x_{0}$, by

$$
\begin{aligned}
\left(T_{0}^{-1} T_{0}^{\prime}\right)_{j j}= & (1 / 2)\left[F_{\lambda \lambda}\left(\lambda_{\jmath}(x), x\right) \lambda_{j}^{\prime}(x)+F_{\lambda x}\left(\lambda_{\jmath}(x), x\right)\right. \\
& \left.+i b_{2}^{\prime}(x) \lambda_{j}^{2}(x)+i b_{1}^{\prime}(x)\right]\left[F_{\lambda}\left(\lambda_{j}(x), x\right)\right]^{-1},
\end{aligned}
$$

or,

$$
\begin{aligned}
\left(T_{0}^{-1} T_{0}^{\prime}\right)_{j j}= & (1 / 2)(d / d x) \log F_{\lambda}\left(\lambda_{j}(x), x\right) \\
& +2^{-1} i\left[b_{2}^{\prime}(x) \lambda_{j}^{2}(x)+b_{1}^{\prime}(x)\right]\left[F_{\lambda}\left(\lambda_{j}(x), x\right)\right]^{-1}
\end{aligned}
$$

and

$$
\begin{aligned}
\left(T_{0}^{-1} T_{0}^{\prime}\right)_{j k}= & {\left[\lambda_{k}\left(i b_{2}^{\prime} \lambda_{k} \lambda_{\jmath}+i b_{1}^{\prime}\right)+m^{\prime} \lambda_{k} \lambda_{\jmath}+n^{\prime}\right] } \\
& \times\left[\left(\lambda_{k}-\lambda_{\jmath}\right) F_{\lambda}\left(\lambda_{\jmath}(x), x\right)\right]^{-1}, \quad k \neq j .
\end{aligned}
$$

Let

$$
\begin{aligned}
\lambda_{j}^{(1)} & =-\left(T_{0}^{-1} T_{0}^{\prime}\right)_{i j}, \\
\Lambda_{1} & =\operatorname{diagonal}\left[\lambda_{j}^{(1)}\right] .
\end{aligned}
$$

We note that the $\lambda_{j}^{(1)}(x)$ are continuous for $x \geqq x_{0}$. Let the matrix $T_{2}$ be defined by the equations

$$
\begin{aligned}
& \left(T_{2}\right)_{j j}=0, \\
& \left(T_{2}\right)_{j k}=-\left(T_{0}^{-1} T_{0}^{\prime}\right)_{j k}\left(\lambda_{k}-\lambda_{\jmath}\right)^{-1}, \quad k \neq j .
\end{aligned}
$$

$T_{2}$ has been defined so that $\Lambda_{0} T_{2}-T_{2} \Lambda_{0}-T_{0}^{-1} T_{0}^{\prime}$ is a diagonal matrix; indeed,

$$
\Lambda_{0} T_{2}-T_{2} \Lambda_{0}-T_{0}^{-1} T_{0}^{\prime}=\Lambda_{1}
$$

Thus, $T_{0}$ and $T_{2}$ in the transformation (27) have been chosen so that for $x \geqq x_{0}$, equation (28) is 


$$
z^{\prime}=\left(\Lambda_{0}+\Lambda_{1}\right) z+B z
$$

We shall now show that for $x \geqq x_{0}, B(x)$ exists and is continuous, and $\|B(x)\|$ is integrable on $\left[x_{0}, \infty\right)$. To do this will require a series of lemmas whose proofs are mostly straightforward or else contained in Fedorjuk [6] and are therefore omitted. For $x \geqq x_{0}$, let

$$
\lambda(x)=\max _{j}\left|\lambda_{j}(x)\right|
$$

Then,

$$
\lambda(x)=|\tau(x)| \max _{j}\left|\eta_{j}(x)\right|=\left|a_{0}^{1 / 3}(x)\right|[1+o(1)] \max _{j}\left|\eta_{j}\right|>0
$$

In the following, the capital letters $C$ and $D$ denote suitably chosen positive constants.

LEMMA $1 . \quad D_{1}\left|a_{0}^{1 / 3}(x)\right| \leqq \lambda(x) \leqq D_{2}\left|a_{0}^{1 / 3}(x)\right|$.

Lemma 2. $\quad C_{1} \lambda(x) \leqq\left|\lambda_{j}(x)-\lambda_{k}(x)\right| \leqq C_{2} \lambda(x), j \neq k$.

Let

$$
\begin{aligned}
& \alpha(x)=\max \left\{\left|b_{2}^{\prime}\right|,\left|m^{\prime}\right| / \lambda,\left|b_{1}^{\prime}\right| / \lambda^{2},\left|n^{\prime}\right| / \lambda^{3}\right\}, \\
& \beta(x)=\max \left\{\left|b_{2}^{\prime \prime}\right|,\left|m^{\prime \prime}\right| / \lambda(x),\left|b_{1}^{\prime \prime}\right| / \lambda^{2}(x),\left|n^{\prime \prime}\right| / \lambda^{3}(x)\right\}, \\
& \delta(x)=\max \left\{\left|b_{2}^{\prime}\right|,\left|m^{\prime}\right| /\left|a_{0}^{1 / 3}\right|,\left|b_{1}^{\prime}\right| /\left|a_{0}^{2 / 3}\right|,\left|n^{\prime}\right| /\left|a_{0}\right|\right\}, \\
& \gamma(x)=\max \left\{\left|b_{2}^{\prime \prime}\right|,\left|m^{\prime \prime}\right| /\left|a_{0}^{1 / 3}\right|,\left|b_{1}^{\prime \prime}\right| /\left|a_{0}^{2 / 3}\right|,\left|n^{\prime \prime}\right| /\left|a_{0}\right|\right\}
\end{aligned}
$$

LEMmA 3. $\alpha(x) \leqq C \delta(x)$.

LEMMA 4. $\beta(x) \leqq C \gamma(x)$.

LeMmA 5. $C_{1} \lambda^{2}(x) \leqq\left|F_{\lambda}\left(\lambda_{j}(x), x\right)\right| \leqq C_{2} \lambda^{2}(x)$.

Lemma $6 . \quad\left|F_{x}\left(\lambda_{j}(x), x\right)\right| \leqq C \lambda^{3}(x) \alpha(x)$.

LEMMA 7. $\left|\left[\lambda_{k}(x)-\lambda_{j}(x)\right] F_{\lambda}\left(\lambda_{j}(x), x\right)\right| \geqq C \lambda^{3}(x)$.

LEMMA 8. $\left|\left[\lambda_{k}(x)-\lambda_{j}(x)\right]^{2} F_{\lambda}\left(\lambda_{j}(x), x\right)\right| \geqq C \lambda^{4}(x)$.

LEMMA 9. $\left|F_{\lambda \lambda}\left(\lambda_{j}(x), x\right)\right| \leqq C \lambda(x)$. 
LeMma $10 .\left|F_{\lambda x}\left(\lambda_{j}(x), x\right)\right| \leqq C \lambda^{2}(x) \alpha(x)$.

LEMMa $11 .\left|\lambda_{j}^{\prime}(x)\right| \leqq C \alpha(x) \lambda(x)$.

If $A=\left(A_{j k}\right)_{j, k=1}^{n}$ is an $n \times n$ matrix, we define the norm $\|A\|$ by $\|A\|=n \max _{j, k}\left|A_{j k}\right|$.

Lemma $12 .\left\|\Lambda_{1}(x)\right\| \leqq C \alpha(x)$.

LEMMA $13 .\left\|T_{0}^{-1}(x) T_{0}^{\prime}(x)\right\| \leqq C \alpha(x)$.

LEMMA $14 .\left\|T_{2}(x)\right\| \leqq C \alpha(x) / \lambda(x)$.

LEMMA $15 .\left\|T_{2}^{\prime}(x)\right\| \leqq C\left\{\alpha^{2}(x)+\beta(x)\right] / \lambda(x)$.

LEMMA 16. $\left[E+T_{2}(x)\right]^{-1}$ exists and is continuous for $x \geqq x_{0}$, and $\left\|\left[E+T_{2}(x)\right]^{-1}\right\| \leqq C$.

LEMMA 17. $B(x)$ exists and is continuous for $x \geqq x_{0}$, and $\|B(x)\| \leqq$ $C\left[\alpha^{2}(x)+\beta(x)\right] / \lambda(x)$.

We note that Lemmas 16 and 17 depend on the fact that $\lim _{x \rightarrow \infty} \alpha(x) / \lambda(x)=0$, which follows from Assumptions II and III.

Lemma 18. $\|B(x)\|$ is integrable on $\left[x_{0}, \infty\right)$.

We note that Lemma 18 follows from Lemma 17, and Assumption V.

It is now possible to show that (48) has three linearly independent solutions which satisfy certain specified boundary conditions at infinity. To that end, we observe that a fundamental matrix $Z_{0}\left(x_{0}, x\right)$ for the homogeneous equation

$$
z^{\prime}=\left(\Lambda_{0}+\Lambda_{1}\right) z, \quad x \geqq x_{0},
$$

is given by

$$
Z_{0}\left(x_{0}, x\right)=\text { diagonal }\left[\exp \int_{x_{0}}^{x}\left(\lambda,(t)+\lambda_{l}^{(1)}(t)\right) d t\right] .
$$

Putting

$$
Z(x)=U(x) Z_{0}\left(x_{0}, x\right)
$$

we find that $Z(x)$ is a matrix solution of (48) for $x \geqq x_{0}$ if $U(x)$ satisfies 


$$
U(x)=C+(K U)(x), \quad x \geqq x_{0},
$$

where $C$ is an arbitrary constant matrix, and $K$ is a linear operator on matrices $U(x)$ such that

$$
(K U(x))_{j k}=\int_{x_{j k}}^{x}\left(Z_{0}(t, x) B(t) U(t) Z_{0}(x, t)\right)_{j k} d t
$$

$x_{j k}$ being an arbitrary number in the interval $\left[x_{0}, \infty\right]$.

Let $M$ be the Banach space of continuous matrices $V(x)$ on $\left[x_{0}, \infty\right)$, with $\|V\|_{M}=\sup _{x \geqq x_{0}}\|V(x)\|<\infty$. For reasons that will appear in Lemmas 19 and 20 below, if Assumption VI (a) or (c) holds, we take $x_{j k}=\infty$; if Assumption VI (b) holds, we take $x_{\jmath k}=x_{0}$. Also, we take $C=E$. $1 / 2$.

LEMMA 19. If $x_{0}$ is sufficiently large, then $K: M \rightarrow M$, and $\|K\|_{M} \leqq$

Proof. From (58) it follows that if $V \in M$ and if $x \geqq x_{0}$, then

$$
\begin{aligned}
\left|((K V)(x))_{\jmath k}\right| \leqq & \mid \int_{x_{j k}}^{x}\left[\exp \int_{t}^{x} \operatorname{Re}\left(\lambda_{\jmath}(s)-\lambda_{k}(s)\right) d s\right] \\
& \times\left[\exp \int_{t}^{x} \operatorname{Re}\left(\lambda_{l}^{(1)}(s)-\lambda_{k}^{(1)}(s)\right) d s\right]\|B(t)\| d t \mid\|V\|_{M}
\end{aligned}
$$

By (41), (43) and (38),

$$
\begin{aligned}
\int_{t}^{x}[ & \left.\lambda_{j}^{(1)}(s)-\lambda_{k}^{(1)}(s)\right] d s \\
= & (1 / 2)\left[\log F_{\lambda}\left(\lambda_{j}(x), x\right)-\log F_{\lambda}\left(\lambda_{j}(t), t\right)\right] \\
(60) \quad & (1 / 2)\left[\log F_{\lambda}\left(\lambda_{k}(x), x\right)-\log F_{\lambda}\left(\lambda_{k}(t), t\right)\right] \\
& +(i / 2) \int_{t}^{x} b_{2}^{\prime}(s)\left\{\lambda_{j}^{2}(s)\left[F_{\lambda}\left(\lambda_{j}(s), s\right)\right]^{-1}-\lambda_{k}^{2}(s)\left[F_{\lambda}\left(\lambda_{k}(s), s\right)\right]^{-1}\right\} d s \\
& +(i / 2) \int_{t}^{x} b_{1}^{\prime}(s)\left\{\left[F_{\lambda}\left(\lambda_{j}(s), s\right)\right]^{-1}-\left[F_{\lambda}\left(\lambda_{k}(s), s\right)\right]^{-1}\right\} d s .
\end{aligned}
$$

It now follows from (36), (49), Lemma 1, Lemma 5, and Assumption IV that $\left|\int_{t}^{x}\left(\lambda_{j}^{(1)}(s)-\lambda_{k}^{(1)}(s)\right) d s\right|$ is bounded for $t, x \geqq x_{0}$. Hence, if $V \in M$, then 
(61)

$\left|((K V)(x))_{j k}\right|$

$$
\leqq C\left|\int_{x_{j k}}^{x}\left[\exp \int_{t}^{x} \operatorname{Re}\left(\lambda_{j}(s)-\lambda_{k}(s)\right) d s\right]\|B(t)\| d t\right|\|V\|_{M}, \quad x \geqq x_{0} .
$$

By our choice of $x_{j k}$, if Assumption VI (a) or (b) holds, $\exp \int_{t}^{x} \operatorname{Re}\left(\lambda_{j}(s)-\right.$ $\left.\lambda_{k}(s)\right) d s \leqq 1$. If Assumption VI (c) holds, then $\mid \int_{t}^{x} \operatorname{Re}\left(\lambda_{j}(s)-\right.$ $\left.\lambda_{k}(s)\right) d s \mid \leqq C_{1}$ for $t, x \geqq x_{0}$, and therefore $\exp \int_{t}^{x} \operatorname{Re}\left(\lambda_{j}(s)-\lambda_{k}(s)\right) d s \leqq$ $\exp C_{1}$. It follows from (61) that

$$
\left|((K V)(x))_{j k}\right| \leqq C \int_{x_{0}}^{\infty}\|B(t)\| d t\|V\|_{M}, \quad x \geqq x_{0}
$$

Hence,

(63) $\|(K V)(x)\|=3 \max _{j, k}\left|((K V)(x))_{j k}\right| \leqq 3 C \int_{x_{0}}^{\infty}\|B(t)\| d t\|V\|_{M}$.

If we now choose $x_{0}$ so large that $\int_{x_{0}}^{\infty}\|B(t)\| d t \leqq 1 / 6 C$, then $\|K\|_{M} \leqq$ 1/2. This proves Lemma 19.

LEMMA 20. If $x_{0}$ is sufficiently large, equation (57) has a unique solution $U(x) \in M$. It is true that $\|(K U)(x)\|=o(1)$ as $x \rightarrow \infty . \quad U(x)$ can be written in the form

$$
U(x)=E+o(1), \quad x \geqq x_{0} .
$$

Proof. The existence and uniqueness of $U(x)$ follows from Lemma 18 and Banach's contraction mapping theorem or successive approximations. To prove that $\|(K U)(x)\|=o(1)$, we observe that if Assumption VI (a) or (c) holds (so that we take $x_{\jmath k}=\infty$ ), then from (61), $\left|((K U)(x))_{j k}\right| \leqq C \int_{x}^{\infty}\|B(t)\| d t\|U\|_{M}=o(1)$. If Assumption VI (b) holds (so that we take $x_{j k}=x_{0}$ ), then from (61),

$$
\begin{aligned}
\left|((K U)(x))_{j k}\right| \leqq & C\left\{\int_{x_{0}}^{x_{1}}\left[\exp \int_{x_{1}}^{x} \operatorname{Re}\left(\lambda_{i}(s)-\lambda_{k}(s)\right) d s\right]\|B(t)\| d t\right. \\
& \left.+\int_{x_{1}}^{x}\|B(t)\| d t\right\}\|V\|_{M},
\end{aligned}
$$

where $x \geqq x_{1} \geqq x_{0}$. From this inequality it is seen that $\left|((K U)(x))_{j k}\right|=$ 
$o(1)$ also when Assumption VI (b) holds. (64) follows from (57) and the fact that $\|(K U)(x)\|=o(1)$. This completes the proof of Lemma 20 .

THEOREM 1. Under Assumptions I-VI, the equation Ly $=i \sigma y, x \geqq$ $r, \sigma \neq 0$, has three linearly independent solutions $y_{k}, k=1,2,3$, of the form

$$
y_{k}=[1+o(1)] a_{0}^{-1 / 3}(x) \exp \int_{x_{0}}^{x} \lambda_{k}(t) d t, \quad x \geqq x_{0},
$$

where the $\lambda_{k}(t)$ are given by equation (22).

Proof. By (56) and (64), there is a solution matrix $Z(x)$ for (48) of the form

$$
Z(x)=[E+o(1)] Z_{0}\left(x_{0}, x\right), \quad x \geqq x_{0} .
$$

If $x_{0}$ is sufficiently large, $\operatorname{det}[E+o(1)] \neq 0$ for $x \geqq x_{0}$ and therefore $Z(x)$ is a fundamental matrix for (48). By (66) and (27) a solution matrix for (25) is given by

$$
W(x)=T_{0}(x)\left[E+T_{2}(x)\right][E+o(1)] Z_{0}\left(x_{0}, x\right), \quad x \geqq x_{0} .
$$

Since $\left[E+T_{2}(x)\right]^{-1}$ exists by Lemma 16 and $T_{0}^{-1}(x)$ exists by $(31), W(x)$ is a fundamental matrix. By Lemma 14 and the fact that $\lim _{x \rightarrow \infty} \alpha(x) / \lambda(x)=0$, we see that

$$
W(x)=T_{0}(x)[E+o(1)] Z_{0}\left(x_{0}, x\right), \quad x \geqq x_{0} .
$$

Let $y_{k}(x)=w_{1 k}(x), k=1,2,3$, where $w_{1 k}(x)$ is the element in the first row and $k$ th column of $W(x)$. Then, by the equivalence of (24) and (25), $y_{k}$ is a solution of (24), and by (68) and (30),

$$
y_{k}=[1+o(1)] \exp \int_{x_{0}}^{x}\left[\lambda_{k}(t)+\lambda_{k}^{(1)}(t)\right] d t, \quad x \geqq a .
$$

From the equations $y_{k}=w_{k 1}, y^{\prime}=w_{k 2}, y_{k}^{\prime \prime}=-\left(i b_{2}\right)^{-1} m w_{k 2}+\left(i b_{2}\right)^{-1} w_{3}$, we see that $W\left(y_{1}, y_{2}, y_{3}\right)(x)=\operatorname{det} W(x) \neq 0, x \geqq x_{0}$, where $W\left(y_{1}, y_{2}, y_{3}\right)$ is the Wronskian of $y_{1}, y_{2}, y_{3}$. Hence, $y_{1}, y_{2}, y_{3}$ are linearly independent for $x \geqq x_{0}$. By (43), (41), (38), (39), (49), Lemma 5, Lemma 1 and Assumption IV we see that

(70) $\exp \int_{x_{0}}^{x} \lambda_{k}^{(1)}(t) d t=C_{k}\left|a_{0}^{-1 / 3}(x)\right|[1+o(1)], \quad x \geqq x_{0}, \quad C_{k} \neq 0$. 
(65) now follows from (69), (70) and the fact that $\left|a_{0}\right| \rightarrow \infty$, so that $a_{0}(x)>0$ or $a_{0}(x)<0$ for $x \geqq x_{0}$. This finishes the proof of Theorem 1 .

3. Asymptotic formulas for the $\lambda_{k}(x)$. In this section we take the coefficients of the operator $L$ of equation (1) to be the following on the interval $[1, \infty)$ :

$$
\begin{aligned}
& b_{2}(x) \equiv 1, \\
& b_{1}(x)=a x^{\alpha}, \quad \alpha<2 \gamma / 3, \\
& a_{1}(x)=b x^{\gamma / 3}, \\
& a_{0}(x)=c x^{\gamma}, \quad \gamma>0, \quad c \neq 0 .
\end{aligned}
$$

Lemma 21. If $b / c^{1 / 3} \neq 3 / 2^{2 / 3}$, then the coefficients of $L$ given by (71)-(74) satisfy Assumptions I-V with

$$
d=b / c^{1 / 3} \text {. }
$$

The proof is straightforward. We note that it is required in (74) that $\gamma>0$ and $c \neq 0$ in order that $a_{0}(x) \rightarrow+\infty$ or $a_{0}(x) \rightarrow-\infty$ (Assumption I). The exponent $\gamma / 3$ occurs in (73) in order that $\lim _{x \rightarrow \infty} a_{1} / a_{0}^{1 / 3}=d$ (Assumption II) with the possibility that $d \neq 0$. The inequality $\alpha<2 \gamma / 3$ is required in (72) in order that $b_{1} / a_{0}^{2 / 3}=o(1)$ (Assumption II).

LEMmA 22. If $b / c^{1 / 3}<3 / 2^{2 / 3}$, the coefficients of $L$ given by (71)-(74) satisfy Assumptions I-VI.

Proof. Since $d=b / c^{1 / 3}<3 / 2^{2 / 3}, h_{0}(\eta)=0$ has one real negative root and two complex conjugate nonreal roots. Suppose $\eta_{02}=p+i q, \eta_{03}=$ $p-i q, q>0$. Then from (23) one sees that Assumption VI is satisfied; in fact, (a) or (b) is true for each pair $j, k$. This proves the lemma.

If $d>3 / 2^{2 / 3}$, then $h_{0}(\eta)=0$ has three real roots. In this case in order to check Assumption VI it is necessary to have asymptotic formulas for the $\lambda_{k}(x)$ which are more precise than (23). We obtain these by use of $(20)$.

LEMMA 23. Suppose the coefficients of $L$ are given by (71)-(74) and that $b / c^{1 / 3} \neq 3 / 2^{2 / 3}$. Then the roots $\lambda_{k}(x)$ of (7) are given by 
(76)

$$
\begin{aligned}
\lambda_{k}(x)= & i a_{0}^{1 / 3}\left\{\eta_{0 k}+\left[\eta_{0 k}-v_{11} d\right](6 c)^{-1}(i D)\right. \\
& +a c^{-2 / 3} v_{10} x^{-\nu}+\left[-\left(\eta_{0 k}-v_{11} d\right)+v_{22} d^{2}\right](6 c)^{-2}(i D)^{2} \\
& -a c^{-2 / 3}\left[v_{10}+v_{21} d\right](6 c)^{-1}(i D) x^{-\nu} \\
& +\left(a c^{-2 / 3}\right)^{2} v_{20} x^{-2 \nu} \\
& +\left[(5 / 3)\left(\eta_{0 k}-v_{11} d\right)-3 v_{22} d^{2}-v_{33} d^{3}\right](6 c)^{-3}(i D)^{3} \\
& +O\left(D^{2} x^{-\nu}\right)+O\left(D x^{-2 \nu}\right)+\left(a c^{-2 / 3}\right)^{3} v_{30} x^{-3 v} \\
& +\sum_{j=4}^{n+2} \sum_{s=1}^{j} O\left(D^{s} x^{-(1-s) \nu}\right)+O\left(D x^{-(n+2) \nu}\right) \\
& +\sum_{j=4}^{n} v_{j 0}\left(a c^{-2 / 3}\right)^{\prime} x^{-j \nu} \\
& +w_{n+1,0}(x)\left(a c^{-2 / 3}\right)^{n+1} x^{-(n+1) \nu} \\
& \left.+w_{n+2,0}(x)\left(a c^{-2 / 3}\right)^{n+2} x^{-(n+2) \nu}\right\}
\end{aligned}
$$

where $n$ is an integer, $n \geqq 4$, the $v_{j s}$ are constants which depend on $\eta_{0 k}$ and are real when $\eta_{0 k}$ is real, $w_{n+1,0}(x)$ and $w_{n+2,0}(x)$ are complex functions which are bounded as $x \rightarrow \infty$,

$$
\begin{aligned}
\nu & =2 \gamma / 3-\alpha>0, \\
D & =a \alpha x^{-(\nu+1+\gamma / 3)}-2 \sigma x^{-\gamma} \\
& =o(1) \text { as } x \rightarrow \infty .
\end{aligned}
$$

If $\eta_{0 k}$ is real,

$$
\begin{aligned}
\operatorname{Re} \lambda_{k}(x)= & a_{0}^{1 / 3}\left\{\left[v_{11} d-\eta_{0 k}\right](6 c)^{-1} D\right. \\
& +a c^{-2 / 3}\left[v_{10}+d v_{21}\right](6 c)^{-1} D x^{-\nu} \\
& -\left[(5 / 3)\left(v_{11} d-\eta_{0 k}\right)+d^{2}\left(3 v_{22}+d v_{33}\right)\right](6 c)^{-3} D^{3} \\
& +O\left(D^{2} x^{-\nu}\right)+O\left(D x^{-2 \nu}\right) \\
& +\sum_{j=4}^{n+2} \sum_{s=1}^{j} O\left(D^{s} x^{-(j-s) \nu}\right)+O\left(D x^{-(n+2) \nu}\right) \\
& \left.+O\left(x^{-(n+1) \nu}\right)+O\left(x^{-(n+2) \nu}\right)\right\}
\end{aligned}
$$

It is true that

$$
\begin{aligned}
& v_{11}=\eta_{0 k}^{2}\left[h_{0}^{\prime}\left(\eta_{0 k}\right)\right]^{-1}, \\
& v_{11} d-\eta_{0 k}=3\left[h_{0}^{\prime}\left(\eta_{0 k}\right)\right]^{-1}, \\
& v_{10}=\eta_{0 k}\left[h_{0}^{\prime}\left(\eta_{0 k}\right)\right]^{-1},
\end{aligned}
$$


(83) $v_{21}=\eta_{0 k}^{2}\left[3 h_{0}^{\prime}\left(\eta_{0 k}\right)-\eta_{0 k} h_{0}^{\prime \prime}\left(\eta_{0 k}\right)\right]\left[h_{0}^{\prime}\left(\eta_{0 k}\right)\right]^{-3}$,

(84) $v_{22}=2^{-1} \eta_{0 k}^{3}\left[4 h_{0}^{\prime}\left(\eta_{0 k}\right)-\eta_{0 k} h_{0}^{\prime \prime}\left(\eta_{0 k}\right)\right]\left[h_{0}^{\prime}\left(\eta_{0 k}\right)\right]^{-3}$,

(85) $v_{33}=2^{-1} \eta_{0 k}^{4}\left\{\left[3 h_{0}^{\prime}\left(\eta_{0 k}\right)-\eta_{0 k} h_{0}^{\prime \prime}\left(\eta_{0 k}\right)\right]^{2}+\left[h_{0}^{\prime}\left(\eta_{0 k}\right)\right]^{2}\right\}\left[h_{0}^{\prime}\left(\eta_{0 k}\right)\right]^{-2}$.

Proof. From (5) and (71)-(74) we see that

$$
\begin{aligned}
& \tau(x)=a_{0}^{1 / 3}(x) t(x), \\
& t(x)=\left[1+(2 c)^{-1}(i D)\right]^{1 / 3} .
\end{aligned}
$$

As $x \rightarrow \infty$,

(88) $t(x)=1+(6 c)^{-1}(i D)-(6 c)^{-2}(i D)^{2}+(5 / 3)(6 c)^{-3}(i D)^{3}+O\left(D^{4}\right)$.

The functions $f_{1}(x)$ and $f_{2}(x)$ of (16)-(18) are given for $x \rightarrow \infty$ by

$$
\begin{aligned}
f_{1}(x)=d[ & \left.-(6 c)^{-1}(i D)+2(6 c)^{-2}(i D)^{2}-(14 / 3)(6 c)^{-3}(i D)^{3}+O\left(D^{4}\right)\right], \\
f_{2}(x)= & a c^{-2 / 3} x^{-\nu}\left[1-2(6 c)^{-1}(i D)\right. \\
& \left.+5(6 c)^{-2}(i D)^{2}-(40 / 3)(6 c)^{-3}(i D)^{3}+O\left(D^{4}\right)\right] .
\end{aligned}
$$

Now, $h^{-1}=h_{0}^{-1}\left[1-\left(\eta / h_{0}\right)\left(\eta f_{1}+f_{2}\right)\right]^{-1}$. Let $n$ be a positive integer. For $\eta \in C_{k}$ and for $x \geqq x_{0}$,

(91)

$$
\begin{aligned}
h^{-1}= & h_{0}^{-1}\left\{1+\sum_{j=1}^{n}\left(\eta / h_{0}\right)^{j}\left(\eta f_{1}+f_{2}\right)^{j}+\left(\eta / h_{0}\right)^{n+1}\left(\eta f_{1}+f_{2}\right)^{n+1}\right. \\
& \left.\times\left[1-\left(\eta / h_{0}\right)\left(\eta f_{1}+f_{2}\right)\right]^{-1}\right\} \\
= & h_{0}^{-1}+\sum_{j=1}^{n}\left(\sum_{s=0}^{j} a_{j s}(\eta) f_{1}^{s} f_{2}^{j-s}\right) \\
& +\sum_{s=0}^{n+1} a_{n+1, s}(\eta) f_{1}^{s} f_{2}^{n+1-s}\left[1-\left(\eta / h_{0}\right)\left(\eta f_{1}+f_{2}\right)\right]^{-1} .
\end{aligned}
$$

Hence,

$$
\begin{aligned}
\eta h_{\eta} h^{-1}= & \eta h_{0}^{\prime} h_{0}^{-1}+\sum_{j=1}^{n+1} \sum_{s=0}^{j} b_{j s}(\eta) f_{1}^{s} f_{2}^{\prime-s} \\
& +\left[\sum_{s=0}^{n+1} c_{n+1, s}(\eta, x) f_{1}^{s} f_{2}^{n+1-s}+\sum_{s=0}^{n+2} c_{n+2, s}(\eta, x) f_{1}^{s} f_{2}^{n+2-s}\right] \\
& \times\left[1-\left(\eta / h_{0}\right)\left(\eta f_{1}+f_{2}\right)\right]^{-1}
\end{aligned}
$$

Substituting (92) into (20), 


$$
\begin{aligned}
\eta_{k}(x)=\eta_{0 k} & +\sum_{j=1}^{n+1} \sum_{s=0}^{j} v_{j s} f_{1}^{s} f_{2}^{i-s} \\
& +\sum_{s=0}^{n+1} w_{n+1, s}(x) f_{1}^{s} f_{2}^{n+1-s} \\
& +\sum_{s=0}^{n+2} w_{n+2, s}(x) f_{1}^{s} f_{2}^{n+2-s}
\end{aligned}
$$

where the $v_{j s}$ are constants which are real if $\eta_{0 k}$ is real, and the functions $w_{n+1, s}(x)$ and $w_{n+2, s}(x)$ are bounded as $x \rightarrow \pm \infty$. If we substitute (93) into (22), we obtain for $x \geqq x_{0}$,

$$
\begin{aligned}
\lambda_{k}(x)= & i a_{0}^{1 / 3}\left\{t \eta_{0 k}+\sum_{j=1}^{3} \sum_{s=0}^{j} v_{j s} t f_{1}^{s} f_{2}^{j-s}\right. \\
& +\sum_{j=4}^{n+1}\left[v_{j 0} t f_{2}^{j}+\sum_{s=1}^{j} v_{i s} t f_{1}^{s} f_{2}^{j-s}\right] \\
& +w_{n+1,0} t f_{2}^{n+1}+\sum_{s=1}^{n+1} w_{n+1, s} t f_{1}^{s} f_{2}^{n+1-s} \\
& \left.+w_{n+2,0} t f_{2}^{n+2}+\sum_{s=1}^{n+2} w_{n+2, s} t f_{1}^{s} f_{2}^{n+2-s}\right\} .
\end{aligned}
$$

We now use (88), (89), (90) to calculate asymptotic expansions for each of the terms $t \eta_{0 k}, t f_{1}^{s} f_{2}^{i-s}$. We obtain

$$
\begin{aligned}
t \eta_{0 k}= & \eta_{0 k}+\eta_{0 k}(6 c)^{-1}(i D)-\eta_{0 k}(6 c)^{-2}(i D)^{2}+(5 / 3) \eta_{0 k}(6 c)^{-3}(i D)^{3} \\
& +O\left(D^{4}\right), \\
t f_{1}= & d\left[-(6 c)^{-1}(i D)+(6 c)^{-2}(i D)^{2}-(5 / 3)(6 c)^{-3}(i D)^{3}+O\left(D^{4}\right)\right], \\
t f_{2}= & a c^{-2 / 3} x^{-\nu}\left[1-(6 c)^{-1}(i D)+O\left(D^{2}\right)\right], \quad \text { etc. }
\end{aligned}
$$

Substituting into (94), we obtain (76). (79) follows immediately from (76). From the way in which (93) was derived, we see that $v_{11}=$ $(2 \pi i)^{-1} \int_{C_{k}}\left[\eta^{3} h_{0}^{\prime}-2 \eta^{2} h_{0}\right] h_{0}^{-2} d \eta$. Hence,

$$
\begin{aligned}
v_{11} & =(2 \pi i)^{-1} \int_{C_{k}}\left[\eta^{2} h_{0}^{-1}-(d / d \eta)\left(\eta^{3} h_{0}^{-1}\right)\right] d \eta \\
& =(2 \pi i)^{-1} \int_{C_{k}} \eta^{2} h_{0}^{-1} d \eta=\eta_{0 k}\left[h_{0}^{\prime}\left(\eta_{0 k}\right)\right]^{-1}
\end{aligned}
$$

This proves (80). (82)-(85) are proved similarly. (81) follows from (80) and the fact that $d=\left(\eta_{0 k}^{3}+1\right) \eta_{0 k}^{-2}$. This proves Lemma 23 . 
Let

(95)

$$
\begin{aligned}
\mu & =\min \{\nu+1+\gamma / 3, \gamma\} \text { if } a \alpha \neq 0 \\
& =\gamma \quad \text { if } \quad a \alpha=0 .
\end{aligned}
$$

Then, as $x \rightarrow \infty$,

$$
D=O\left(x^{-\mu}\right)
$$

In the following we shall consider three cases. Case 1 is the case that $\nu=2 \mu$, which occurs if $\alpha=-4 \gamma / 3$. Case 2 is the case $\nu>2 \mu$, which occurs if $\alpha<-4 \gamma / 3$. Case 3 is the case $\nu<2 \mu$, which occurs if $-4 \gamma / 3<\alpha<2 \gamma / 3$.

LEMma 24. Suppose the coefficients of L are given by (71)-(74) and that $b / c^{1 / 3} \neq 3 / 2^{2 / 3}$. If $\eta_{0 k}$ is real, $\operatorname{Re} \lambda_{k}(x)$ has the following asymptotic expansions:

Case 1. $\nu=2 \mu$ (i.e., $\alpha=-4 \gamma / 3)$. Then,

$$
\begin{aligned}
\operatorname{Re} \lambda_{k}(x)= & a_{0}^{1 / 3}\left\{\left[h_{0}^{\prime}\left(\eta_{0 k}\right)\right]^{-1}(2 c)^{-1} D\right. \\
& +a c^{-2 / 3}\left[v_{10}+d v_{21}\right](6 c)^{-1} D x^{-2 \mu} \\
& -\left[5\left(h_{0}^{\prime}\left(\eta_{0 k}\right)\right)^{-1}+d^{2}\left(3 v_{22}+d v_{33}\right)\right](6 c)^{-3} D^{3} \\
& \left.+O\left(x^{-4 \mu}\right)\right\} .
\end{aligned}
$$

Case 2. $\nu>2 \mu$ (i.e., $\alpha<-4 \gamma / 3$ ). Then,

$\operatorname{Re} \lambda_{k}(x)=a_{0}^{1 / 3}\left\{\left[h_{0}^{\prime}\left(\eta_{0 k}\right)\right]^{-1}(2 c)^{-1} D\right.$

$$
\left.-\left[5\left(h_{0}^{\prime}\left(\eta_{0 k}\right)\right)^{-1}+d^{2}\left(3 v_{22}+d v_{33}\right)\right](6 c)^{-3} D^{3}+O\left(x^{-3 \mu-\epsilon}\right)\right\},
$$

where $\epsilon>0$.

Case 3. $\quad \nu<2 \mu$ (i.e., $-4 \gamma / 3<\alpha<2 \gamma / 3$ ). Then,

$$
\begin{aligned}
\operatorname{Re} \lambda_{k}(x)= & a_{0}^{1 / 3}\left\{\left[h_{0}^{\prime}\left(\eta_{0 k}\right)\right]^{-1}(2 c)^{-1} D\right. \\
& +a c^{-2 / 3}\left[v_{10}+d v_{21}\right](6 c)^{-1} D x^{-\nu} \\
& \left.+O\left(x^{-\mu-\nu-\epsilon}\right)\right\}
\end{aligned}
$$

where $\epsilon>0$. 
Proof. (97) and (98) follow directly from (79). If we choose $n$ so large that $n \nu>\mu$, then we also see that (99) follows from (79). This proves Lemma 24.

LEMMA 25. If $b / c^{1 / 3}>3 / 2^{2 / 3}, b / c^{1 / 3} \neq 3 / 2^{1 / 3}$, and $\sigma \neq a \alpha / 2$, then the coefficients of $L$ given by (71)-(74) satisfy Assumptions I-VI.

Proof. Since $d=b / c^{1 / 3}>3 / 2^{2 / 3}, \quad h_{0}(\eta)=0 \quad$ has three real roots. Because $d \neq 3 / 2^{1 / 3}, h_{0}^{\prime}\left(\eta_{01}\right), h_{0}^{\prime}\left(\eta_{02}\right), h_{0}^{\prime}\left(\eta_{03}\right)$ are all distinct. From (78) and (95) we see that $D=C_{1} x^{-\mu}[1+o(1)]$, where $C_{1} \neq 0$ because $\sigma \neq a \alpha / 2$. By Lemma 24,

$$
\begin{aligned}
\operatorname{Re}\left[\lambda_{j}(x)-\lambda_{k}(x)\right]= & C_{1}(2 c)^{-1} a_{0}^{1 / 3}\left\{\left[h_{0}^{\prime}\left(\eta_{0_{J}}\right)\right]^{-1}-\left[h_{0}^{\prime}\left(\eta_{0 k}\right)\right]^{-1}\right\} \\
& \times x^{-\mu}[1+o(1)]
\end{aligned}
$$

From (100) and (74) it follows that Assumption VI is satisfied. This proves Lemma 25.

LEMMA 26. Suppose the coefficients of $L$ are given by (71)-(74) and that $b / c^{1 / 3}=3 / 2^{1 / 3}$. Then the roots of $h_{0}(\eta)=0$ are $\eta_{01}=2^{-1 / 3}\left(1-3^{1 / 2}\right)$, $\eta_{02}=2^{-1 / 3}, \eta_{03}=2^{-1 / 3}\left(1+3^{1 / 2}\right)$, and

$$
\begin{aligned}
& h_{0}^{\prime}\left(\eta_{01}\right)=h_{0}^{\prime}\left(\eta_{03}\right) \neq h_{0}^{\prime}\left(\eta_{02}\right), \\
& v_{10}\left(\eta_{01}\right)+d v_{21}\left(\eta_{01}\right)=3^{-1} 2^{-2 / 3}\left(-2+3^{1 / 2}\right), \\
& v_{10}\left(\eta_{03}\right)+d v_{21}\left(\eta_{03}\right)=3^{-1} 2^{-2 / 3}\left(-2-3^{1 / 2}\right), \\
& 3 v_{22}\left(\eta_{01}\right)+d v_{33}\left(\eta_{01}\right)=3^{-1} 2^{-2 / 3}\left[250-(143) 3^{1 / 2}\right], \\
& 3 v_{22}\left(\eta_{03}\right)+d v_{33}\left(\eta_{03}\right)=3^{-1} 2^{-2 / 3}\left[250+(143) 3^{1 / 2}\right] .
\end{aligned}
$$

The proof follows immediately from (80)-(85) and the fact that $h_{0}(\eta)=\eta^{3}-\left(3 / 2^{1 / 3}\right) \eta^{2}+1$.

Lemma 27. Suppose that $b / c^{1 / 3}=3 / 2^{1 / 3}, \alpha<-4 \gamma / 3$. Then, the coefficients of $L$ given by (71)-(74) satisfy Assumptions I-VI.

Proof. Since $\alpha<-4 \gamma / 3, \nu+1+\gamma / 3>\gamma$. By (95), $\mu=\gamma$. By (78), $D=-2 \sigma x^{-\gamma}(1+o(1))$. From (101) and (98) it follows that $\operatorname{Re}\left[\lambda_{2}(x)-\lambda_{1}(x)\right]$ and $\operatorname{Re}\left[\lambda_{2}(x)-\lambda_{3}(x)\right]$ satisfy (a), (b) or (c) of Assumption VI. From (98), (101), (104), (105),

$$
\operatorname{Re}\left[\lambda_{3}(x)-\lambda_{1}(x)\right]=C_{1} x^{-8 \gamma / 3}(1+o(1))
$$


where $C_{1} \neq 0$. Thus, $\operatorname{Re}\left[\lambda_{3}(x)-\lambda_{1}(x)\right]$ also satisfies (a), (b) or (c) of Assumption VI. This proves Lemma 27.

LEMMA 28. Suppose that $b / c^{1 / 3}=3 / 2^{1 / 3},-4 \gamma / 3<\alpha<2 \gamma / 3, \quad \sigma \neq$ $a \alpha / 2, a \neq 0$. Then, the coefficients of $L$ given by (71)-(74) satisfy Assumptions I-VI.

Proof. It follows from (78) that $D=C_{1} x^{-\mu}(1+o(1))$, where $C_{1} \neq 0$ because $\sigma \neq a \alpha / 2$. By (101) and (99), $\operatorname{Re}\left[\lambda_{2}(x)-\lambda_{1}(x)\right]$ and $\operatorname{Re}\left[\lambda_{2}(x)-\right.$ $\lambda_{3}(x)$ ] satisfy (a), (b) or (c) of Assumption VI. From (99) and (101)-(103), $\operatorname{Re}\left[\lambda_{3}(x)-\lambda_{1}(x)\right]=C_{2} x^{-\mu-\nu+\gamma / 3}(1+o(1))$, where $C_{2} \neq 0$ because $a \neq 0$. Hence, $\operatorname{Re}\left[\lambda_{3}(x)-\lambda_{1}(x)\right]$ satisfies (a), (b) or (c) of Assumption VI. This proves Lemma 28.

LEMMA 29. Suppose that $b / c^{1 / 3}=3 / 2^{1 / 3}, \quad \alpha=-4 \gamma / 3, \quad \sigma^{2} \neq$ $-2^{2 / 3} a c^{4 / 3} / 143$. Then, the coefficients of $L$ given by (71)-(74) satisfy Assumptions I-VI.

Proof. Since $\alpha=-4 \gamma / 3, \mu=\gamma$. Hence, $D=-2 \sigma x^{-\gamma}(1+o(1))$ by (78). From (101) and (97) it follows that $\operatorname{Re}\left[\lambda_{2}(x)-\lambda_{1}(x)\right]$ and $\operatorname{Re}\left[\lambda_{2}(x)-\lambda_{3}(x)\right]$ satisfy (a), (b) or (c) of Assumption VI. From (97) and (101)-(105), $\operatorname{Re}\left[\lambda_{3}(x)-\lambda_{1}(x)\right]=C_{1} x^{-8 \gamma / 3}(1+o(1))$, where $C_{1} \neq 0$ because $\sigma^{2} \neq-2^{2 / 3} a c^{4 / 3} / 143$. Hence, $\operatorname{Re}\left[\lambda_{3}(x)-\lambda_{1}(x)\right]$ satisfies (a), (b) or (c) of Assumption VI. This proves Lemma 29.

LEMMA 30. Suppose the coefficients of $L$ are given by (71)-(74) and that $b / c^{1 / 3} \neq 3 / 2^{2 / 3}$. If $\eta_{0 k}$ is real, $\operatorname{Re} \lambda_{k}(x)$ has the following asymptotic expansions:

Case A. Suppose $a=0$. Then,

$$
\operatorname{Re} \lambda_{k}(x)=-\sigma\left[h_{0}^{\prime}\left(\eta_{0 k}\right)\right]^{-1} c^{-2 / 3} x^{-2 \gamma / 3}(1+o(1)) .
$$

Case B. Suppose $a \neq 0$.

(i) Suppose $1<2 \gamma / 3$.

(a) If $1<\alpha<2 \gamma / 3$, then

$$
\operatorname{Re} \lambda_{k}(x)=a \alpha c^{-2 / 3}\left[2 h_{0}^{\prime}\left(\eta_{0 k}\right)\right]^{-1} x^{\alpha-1-2 \gamma / 3}(1+o(1)) .
$$

(b) If $\alpha=1$ and $\sigma \neq a / 2$, 
(c) If $\alpha<1$, (106) is valid.

(ii) If $\alpha<2 \gamma / 3 \leqq 1$, (106) is valid.

The proof follows directly from Lemma 24 with calculation of $\mu$ and $D$ in the various cases.

4. The deficiency index of the operator $L$. In the following, $L_{2}$ will denote the space $L_{2}[1, \infty)$, i.e., the space of complexvalued functions on $[1, \infty)$ which have Lebesgue square integrable absolute values.

LEMMA 31. Suppose the coefficients of $L$ are given by (71)-(74) and that $b / c^{1 / 3}<3 / 2^{2 / 3}$, so that $\eta_{0 k}=u_{k}+i v_{k}$, where $v_{2}>0$ and $v_{3}<0$. Then the function $f_{k}(x)=a_{0}^{-1 / 3}(x) \exp \int_{x_{0}}^{x} \lambda_{k}(t) d t, x \geqq x_{0}$, has the following properties:

(i) If $k=2$ and $c>0$ or if $k=3$ and $c<0$, then $f_{k} \in L_{2}$ for $\sigma>0$ and for $\sigma<0$.

(ii) If $k=2$ and $c<0$ or if $k=3$ and $c>0$, then $f_{k} \notin L_{2}$ for $\sigma>0$ and for $\sigma<0$.

Proof. We shall give an intuitive proof which can be made precise as in Naimark [9, §23]. We have by (23) that

$$
\begin{aligned}
\left|f_{k}(x)\right| & \approx|c|^{-1 / 3} x^{-\gamma / 3} \exp \left[-v_{k} c^{1 / 3} \int_{x_{0}}^{x} t^{\gamma / 3} d t\right] \\
& =|c|^{-1 / 3} x^{-\gamma / 3} \exp \left[-v_{k} c^{1 / 3}(\gamma / 3+1)^{-1}\left(x^{\gamma / 3+1}-x_{0}^{\gamma / 3+1}\right)\right] \\
& \rightarrow+\infty \quad \text { if } \quad v_{k} c^{1 / 3}<0 .
\end{aligned}
$$

This proves (ii). Also,

$$
\begin{aligned}
\left|f_{k}(x)\right|^{2} & \approx|c|^{-2 / 3} x^{-2 \gamma / 3} \exp \left[-2 v_{k} c^{1 / 3} \int_{x_{0}}^{x} t^{\gamma / 3} d t\right] \\
& \leqq|c|^{-2 / 3} x^{\gamma / 3} \exp \left[-2 v_{k} c^{1 / 3} \int_{x_{0}}^{x} t^{\gamma / 3} d t\right] \\
& =\left(-2 v_{k} c\right)^{-1}(d / d x) \exp \left[-2 v_{k} c^{1 / 3} \int_{x_{0}}^{x} t^{\gamma / 3} d t\right]
\end{aligned}
$$

This proves (i).

LEMMA 32. Suppose the coefficients of $L$ are given by (71)-(74) and that $b / c^{1 / 3} \neq 3 / 2^{2 / 3}$. If $\eta_{0 k}$ is real, the function $f(x)=a_{0}^{-1 / 3}(x)$ 
$\exp \int_{x_{0}}^{x} \lambda_{k}(t) d t, x \geqq x_{0}$, has the following properties:

(I) If $2 \gamma / 3>1$ and $\sigma \neq a / 2$, then $f \in L_{2}$ for $\sigma>0$ and for $\sigma<0$.

(II) If $2 \gamma / 3 \leqq 1$, then $f \in L_{2}$ for $\sigma / h_{0}^{\prime}\left(\eta_{0 k}\right)>0$, and $f \notin L_{2}$ for $\sigma / h_{0}^{\prime}\left(\eta_{0 k}\right)<0$.

Proof. Case A. Suppose $a=0$. By (106),

$$
\begin{aligned}
|f(x)|^{2} & \approx c^{-2 / 3} x^{-2 \gamma / 3} \exp \left\{-2 \sigma c^{-2 / 3}\left[h_{0}^{\prime}\left(\eta_{0 k}\right)\right]^{-1} \int_{x_{0}}^{x} t^{-2 \gamma / 3} d t\right\} \\
& =(-2 \sigma)^{-1} h_{0}^{\prime}\left(\eta_{0 k}\right)(d / d x) \exp \left\{-2 \sigma c^{-2 / 3}\left[h_{0}^{\prime}\left(\eta_{0 k}\right)\right]^{-1} \int_{x_{0}}^{x} t^{-2 \gamma / 3} d t\right\} .
\end{aligned}
$$

From this last expression we see that (I) and (II) are true for Case A.

Case B. Suppose $a \neq 0$. If $1<\alpha<2 \gamma / 3$, then by (107),

$$
\begin{aligned}
|f(x)|^{2} & \approx c^{-2 / 3} x^{-2 \gamma / 3} \exp \left\{a \alpha c^{-2 / 3}\left[h_{0}^{\prime}\left(\eta_{0 k}\right)\right]^{-1} \int_{x_{0}}^{x} t^{\alpha-1-2 \gamma / 3} d t\right\} \\
& \leqq c^{-2 / 3} x^{\alpha-1-2 \gamma / 3} \exp \left\{a \alpha c^{-2 / 3}\left[h_{0}^{\prime}\left(\eta_{0 k}\right)\right]^{-1} \int_{x_{0}}^{x} t^{\alpha-1-2 \gamma / 3} d t\right\} \\
& =(a \alpha)^{-1} h_{0}^{\prime}\left(\eta_{0 k}\right)(d / d x) \exp \left\{a \alpha c^{-2 / 3}\left[h_{0}^{\prime}\left(\eta_{0 k}\right)\right]^{-1} \int_{x_{0}}^{x} t^{\alpha-1-2 \gamma / 3} d t\right\} .
\end{aligned}
$$

Since $\int_{x_{0}}^{x} t^{\alpha-1-2 \gamma / 3} d t$ converges, we see that (I) is true if $1<\alpha<2 \gamma / 3$. If $\alpha=1<2 \gamma / 3$ and $\sigma \neq a / 2$, then by (108),

$$
\begin{aligned}
|f(x)|^{2} \approx & c^{-2 / 3} x^{-2 \gamma / 3} \exp \left\{(a-2 \sigma) c^{-2 / 3}\left[h_{0}^{\prime}\left(\eta_{0 k}\right)\right]^{-1} \int_{x_{0}}^{x} t^{-2 \gamma / 3} d t\right\} \\
=(a-2 \sigma)^{-1} h_{0}^{\prime}\left(\eta_{0 k}\right) & \quad \times(d / d x) \exp \left\{(a-2 \sigma) c^{-2 / 3}\left[h_{0}^{\prime}\left(\eta_{0 k}\right)\right]^{-1} \int_{x_{0}}^{x} t^{-2 \gamma / 3} d t\right\} .
\end{aligned}
$$

Since $\int_{x_{0}}^{x} t^{-2 \gamma / 3} d t$ converges, we see that (I) is true for $\alpha=1<2 \gamma / 3$ and $\sigma \neq a / 2$. If $\alpha<1<2 \gamma / 3$ or if $\alpha<2 \gamma / 3 \leqq 1$, then by Lemma 30, (106) is valid and therefore (I) and (II) follow as in Case A. This proves Lemma 32.

Let $n_{+}$denote the dimension of the space of solutions of $L y=i \sigma y$, $x \geqq r$, which are in $L_{2}[r, \infty)$ for $\sigma>0$. It is known that $n_{+}$is independent of $\sigma$. Let $n_{-}$denote the same number for $\sigma<0$. We shall call $n_{+}$and 
$n_{-}$the deficiency numbers of $L$, and we shall call the pair $\left(n_{+}, n_{-}\right)$the deficiency index.

THEOREM 2. Suppose that the coefficients of $L$ are given by (71)-(74) and that $b / c^{1 / 3}<3 / 2^{2 / 3}$. If $2 \gamma / 3>1, n_{+}=n_{-}=2$. If $2 \gamma / 3 \leqq 1, n_{+}=2$, $n_{-}=1$.

Proof. By Lemma 22, the coefficients of $L$ satisfy Assumptions I-VI. By Theorem $1, L y=i \sigma y, x \geqq 1, \sigma \neq 0$, has three linearly independent solutions $y_{k}$ given by (65). By Lemma 31, for $c>0, y_{2} \in L_{2}$ and $y_{3} \notin L_{2}$ for $\sigma>0$ and for $\sigma<0$; for $c<0, y_{2} \notin L_{2}$ and $y_{3} \in L_{2}$ for $\sigma>0$ and for $\sigma<0$. By Lemma 32, if $2 \gamma / 3>1, y_{1} \in L_{2}$ for $\sigma>0$ and for $\sigma<0, \sigma \neq a / 2$; if $2 \gamma / 3 \leqq 1, y_{1} \in L_{2}$ for $\sigma>0$, and $y_{2} \notin L_{2}$ for $\sigma<0$, because $h_{0}^{\prime}\left(\eta_{01}\right)>0$. It follows that if $2 \gamma / 3>1$, then $n_{+}=n_{-}=2$, and if $2 \gamma / 3 \leqq 1$, then $n_{+}=2$. It also follows that if $2 \gamma / 3 \leqq 1$, then $n_{-}=1$, provided we can show that for $c>0$ and $\sigma<0$ no nontrivial linear combination of $y_{1}$ and $y_{3}$ is in $L_{2}$, and for $c<0$ and $\sigma<0$ no nontrivial linear combination of $y_{1}$ and $y_{2}$ is in $L_{2}$. We deal with the case $c>0$, $\sigma<0$; the case $c<0$ and $\sigma<0$ is similar. It is sufficient to show that $y_{1}+B y_{3} \notin L_{2}$ if $B \neq 0$. By Theorem 1, (23), and Lemma 30,

$$
\begin{aligned}
\left|y_{1} / y_{3}\right| & =[1+o(1)] \exp \int_{x_{0}}^{x}\left[\operatorname{Re} \lambda_{1}(t)-\operatorname{Re} \lambda_{3}(t)\right] d t \\
& =[1+o(1)] \exp c^{1 / 3} v_{3} \int_{x_{0}}^{x} t^{\gamma / 3}[1+o(1)] d t \rightarrow 0 \quad \text { as } \quad x \rightarrow+\infty .
\end{aligned}
$$

Hence, for $x \geqq x_{1},\left|y_{1} / y_{3}+B\right|^{2} \geqq K$, where $K$ is a constant. Thus

$$
\int_{x_{1}}^{\infty}\left|y_{1}+B y_{3}\right|^{2} d x=\int_{x_{1}}^{\infty}\left|y_{3}\right|^{2}\left|y_{1} / y_{3}+B\right|^{2} d x \geqq K \int_{x_{1}}^{\infty}\left|y_{3}\right|^{2} d x
$$

It follows that $y_{1}+B y_{3} \notin L_{2}$. This completes the proof of Theorem 2 .

THEOREM 3. Suppose that the coefficients of L are given by (71)-(74) and that $b / c^{1 / 3}>3 / 2^{2 / 3}$.

Case A. Suppose $b / c^{1 / 3} \neq 3 / 2^{1 / 3}$. If $2 \gamma / 3>1, \quad n_{+}=n_{-}=3$. If $2 \gamma / 3 \leqq 1, n_{+}=2, n_{-}=1$.

Case B. Suppose $b / c^{1 / 3}=3 / 2^{1 / 3}$ and $\alpha \leqq-4 \gamma / 3$. If $2 \gamma / 3>1, n_{+}=$ $n_{-}=3$. If $2 \gamma / 3 \leqq 1 / 4, n_{+}=2, n_{-}=1$.

Case C. Suppose $b / c^{1 / 3}=3 / 2^{1 / 3}, \quad-4 \gamma / 3<\alpha<2 \gamma / 3, \quad a \neq 0 . \quad$ If $2 \gamma / 3>1, n_{+}=n_{-}=3$. If $4 \gamma / 3-1 \leqq \alpha<2 \gamma / 3<1$, then $n_{+}=2, n_{-}=1$. 
Proof. By Lemmas 25-29, the coefficients of $L$ satisfy Assumptions I-VI in all three cases, provided $\sigma \neq a \alpha / 2$ and $\sigma^{2} \neq-2^{2 / 3} a c^{4 / 3} / 143$. Hence, if we avoid these values of $\sigma, L y=i \sigma y, x \geqq 1, \sigma \neq 0$, has three linearly independent solutions $y_{k}$ given by (65). By Lemma 32 we have the following: (I) If $2 \gamma / 3>1$ and $\sigma \neq a / 2$, then $y_{1}, y_{2}, y_{3} \in L_{2}$ for $\sigma>0$ and for $\sigma<0$; (II) if $2 \gamma / 3 \leqq 1$, then for $\sigma>0, y_{1}, y_{3} \in L_{2}$ and $y_{2} \notin L_{2}$, while for $\sigma<0, y_{2} \in L_{2}$ and $y_{1}, y_{3} \notin L_{2}$. By (I) we see that if $2 \gamma / 3>1$, then $n_{+}=n_{-}=3$ in all three cases. If $2 \gamma / 3 \leqq 1$, then $n_{+}=2$ and $n_{-}=1$, provided we can show that no non-trivial linear combination of $y_{1}$ and $y_{3}$ is in $L_{2}$. Using (106), this can be proved for Case $A$ as in the proof of Theorem 2. In Cases B and C it is necessary to use (97)-(99). The assumptions in Cases $\mathrm{B}$ and $\mathrm{C}$ enable one to do this as in the proof of Theorem 2. This completes the proof of Theorem 3.

THEOREM 4. Suppose that the coefficients of L are given by (71-74) (without the requirements that $\alpha<2 \gamma / 3, \gamma>0$ ). Then the deficiency index of $L$ is as follows for the indicated values of the parameters $\gamma, \alpha$ :

I. $\gamma>3 / 2, \alpha<2 \gamma / 3:(2,2)$ if $b / c^{1 / 3}<3 / 2^{2 / 3} ;(3,3)$ if $b / c^{1 / 3}>3 / 2^{2 / 3}$, $b / c^{1 / 3} \neq 3 / 2^{1 / 3}$.

II. $0<\gamma \leqq 3 / 2, \alpha<2 \gamma / 3:(2,1)$ if $b / c^{1 / 3} \neq 3 / 2^{2 / 3}$ and $b / c^{1 / 3} \neq 3 / 2^{1 / 3}$.

III. $\gamma \leqq 0, \alpha \leqq 0:(2,1)$.

IV. $0<\alpha \leqq 1, \alpha>2 \gamma / 3:(2,1)$.

V. $1<\alpha, \alpha>2 \gamma / 3:(3,3)$ if $a>0 ;(2,2)$ if $a<0$.

Proof. The statements for regions I and II follow from Theorems 2 and 3. III follows from the fact that $n_{+}+n_{-}=3$ by Dunford and Schwartz [4, XIII. 10. E.II(5)] and from the fact that $2 \leqq n_{+}$and $1 \leqq n_{-}$by Everitt [5] or Kogan and Rofe-Beketov [8]. IV and $V$ follow from Unsworth [12]. This proves Theorem 4.

Remark 1. Note that $\alpha=2 \gamma / 3, \gamma>0$, is the only portion of the $(\gamma, \alpha)$-plane not included in Theorem 4 .

Remark 2. The results of $\S 7$ of Pfeiffer [5] are included in Theorem 4 except for the case $c=0$.

\section{REFERENCES}

1. F. V. Atkinson, Discrete and Continuous Boundary Problems, Academic Press, New York, 1964.

2. R. Bellman, Stability Theory of Differential Equations, McGraw-Hill Book Company, New York, 1953.

3. A. Devinatz, The deficiency index of certain fourth-order ordinary self-adjoint differential operators, Quart. J. Math. (Oxford) (2), 23 (1972), 267-286. 
4. N. Dunford and J. T. Schwartz, Linear Operators. Part II: Spectral Theory, Interscience Publishers, New York, 1963.

5. W. N. Everitt, Integrable-square solutions of ordinary differential equations, Quart. J. Math. (Oxford) (2), 10 (1959), 145-155.

6. M. V. Fedorjuk, Asymptotic methods in the theory of one-dimensional singular differential operators, Transactions of the Moscow Mathematical Society, 15 (1966), 333-386. English translation, Amer. Math. Soc.

7. V. I. Kogan and F. S. Rofe-Beketov, The deficiency indices of differential operators of odd order, Kharkov Ped. Inst. named after Lenin, Materials of the sci. and techn. conference on results of sci. work in 1969, publ. by Kharkov State Univ., 1970, No. 7, 93-95.

8. - On the question of the deficiency indices of differential operators with complex coefficients, Proc. Roy. Soc. Edinburgh Sect. A72, part 4, (1975), 281-298.

9. M. A. Naimark, Linear Differential Operators, English translation, Frederick Ungar Pub. Co., New York, 1968.

10. G. W. Pfeiffer, Deficiency indices of a third order equation, Differential Equations, 11 (1972), 474-490.

11. R. A. Shirikyan, Asymptotic methods in the theory of odd-order one-dimensional singular differential operators, Differentsial'nye Uravneniya, 3 (1967), 1942-1956.

12. K. Unsworth, Asymptotic expansions and deficiency indices associated with third-order selfadjoint differential operators, Quart. J. Math. (Oxford) (2), 24 (1973), 177-188.

Received September 4, 1974 and in revised form March 1, 1976. This work was supported in part by the National Science Foundation, Grants GP 36640 and GP 36640 A-1.

CALifornia State University - Fullerton

FULLERTON, CA 92634 


\section{PACIFIC JOURNAL OF MATHEMATICS}

\section{EDITORS}

RichaRd ARENS (Managing Editor)

University of California

Los Angeles, CA 90024

\section{R. A. Beaumont}

University of Washington

Seattle, WA 98105

C. C. Moore

University of California

Berkeley, CA 94720
J. DugunduI

Department of Mathematics

University of Southern California

Los Angeles, CA 90007

R. Finn AND J. Milgram

Stanford University

Stanford, CA 94305

\section{ASSOCIATE EDITORS}
E. F. BECKENBACH
B. H. NeumanN
F. WOLF
K. YoshidA

\section{SUPPORTING INSTITUTIONS}

UNIVERSITY OF BRITISH COLUMBIA

CALIFORNIA INSTITUTE OF TECHNOLOGY

UNIVERSITY OF CALIFORNIA

MONTANA STATE UNIVERSITY

UNIVERSITY OF NEVADA

NEW MEXICO STATE UNIVERSITY

OREGON STATE UNIVERSITY

UNIVERSITY OF OREGON

OSAKA UNIVERSITY

\author{
UNIVERSITY OF SOUTHERN CALIFORNIA \\ STANFORD UNIVERSITY \\ UNIVERSITY OF HAWAII \\ UNIVERSITY OF TOKYO \\ UNIVERSITY OF UTAH \\ WASHINGTON STATE UNIVERSITY \\ UNIVERSITY OF WASHINGTON \\ AMERICAN MATHEMATICAL SOCIETY
}

The Supporting Institutions listed above contribute to the cost of publication of this Journal, but they are not owners or publishers and have no responsibility for its contents or policies.

Mathematical papers intended for publication in the Pacific Journal of Mathematics should be in typed form or offset-reproduced (not dittoed), double spaced with large margins. Underline Greek letters in red, German in green, and script in blue. The first paragraph or two must be capable of being used separately as a synopsis of the entire paper. Items of the bibliography should not be cited there unless absolutely necessary, in which case they must be identified by author and Journal, rather than by item number. Manuscripts, in duplicate, may be sent to any one of the four editors. Please classify according to the scheme of Math. Reviews, Index to Vol. 39. All other communications should be addressed to the managing editor, or Elaine Barth, University of California, Los Angeles, California, 90024.

100 reprints are provided free for each article, only if page charges have been substantially paid. Additional copies may be obtained at cost in multiples of 50 .

The Pacific Journal of Mathematics is issued monthly as of January 1966. Regular subscription rate: $\$ 72.00$ a year (6 Vols., 12 issues). Special rate: $\$ 36.00$ a year to individual members of supporting institutions.

Subscriptions, orders for back numbers, and changes of address should be sent to Pacific Journal of Mathematics, 103 Highland Boulevard, Berkeley, California, 94708.

PUBLISHED BY PACIFIC JOURNAL OF MATHEMATICS, A NON-PROFIT CORPORATION

Printed at Jerusalem Academic Press, POB 2390, Jerusalem, Israel. 


\section{Pacific Journal of Mathematics}

Vol. 68, No. 2

April, 1977

William Allen Adkins, Aldo Andreotti and John Vincent Leahy, An analogue of Oka's theorem for weakly normal complex spaces ........

Ann K. Boyle, M. G. Deshpande and Edmund H. Feller, On nonsingularly

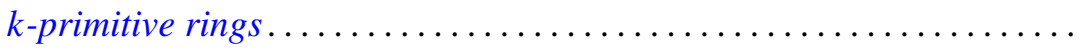

Rolando Basim Chuaqui, Measures invariant under a group of

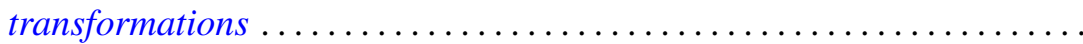

Wendell Dan Curtis and Forrest Miller, Gauge groups and classification of bundles with simple structural group .......................

Garret J. Etgen and Willie Taylor, The essential uniqueness of bounded nonoscillatory solutions of certain even order differential equations

Paul Ezust, On a representation theory for ideal systems

Richard Carl Gilbert, The deficiency index of a third order operator ........

John Norman Ginsburg, $S$-spaces in countably compact spaces using Ostaszewski's method.

Basil Gordon and S. P. Mohanty, On a theorem of Delaunay and some

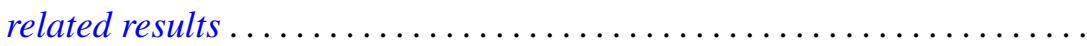

Douglas Lloyd Grant, Topological groups which satisfy an open mapping

theorem.

Charles Lemuel Hagopian, A characterization of solenoids

Kyong Taik Hahn, On completeness of the Bergman metric and its

subordinate metrics. II .

G. Hochschild and David Wheeler Wigner, Abstractly split group extensions.

Gary S. Itzkowitz, Inner invariant subspaces ...............

Jiang Luh and Mohan S. Putcha, A commutativity theorem for

non-associative algebras over a principal ideal domain.

Donald J. Newman and A. R. Reddy, Addendum to: "Rational approximation of $e^{-x}$ on the positive real axis".....

Akio Osada, On the distribution of a-points of a strongly annular function ....

Jeffrey Lynn Spielman, A characterization of the Gaussian distribution in a Hilbert space. .

Robert Moffatt Stephenson Jr., Symmetrizable-closed spaces ...

Peter George Trotter and Takayuki Tamura, Completely semisimple inverse $\Delta$-semigroups admitting principal series . . . . . . . .

Charles Irvin Vinsonhaler and William Jennings Wickless, Torsion free abelian groups quasi-projective over their endomorphism rings...

Frank Arvey Wattenberg, Topologies on the set of closed subsets ... 